\title{
A comprehensive evaluation of food fortification with folic acid for the primary prevention of neural tube defects Shiliang Liu ${ }^{1}$, Roy West ${ }^{2}$, Edward Randell ${ }^{3}$, Linda Longerich ${ }^{2}$, Kathleen Steel O'Connor ${ }^{4}$, Helen Scott ${ }^{5}$, Marian Crowley ${ }^{6}$, Angeline Lam ${ }^{3,7}$, Victor Prabhakaran ${ }^{8}$ and Catherine McCourt*1
}

\begin{abstract}
Address: ${ }^{1}$ Health Surveillance and Epidemiology Division, Centre for Healthy Human Development, PPHB, Health Canada, Ottawa, Ontario, Canada, ${ }^{2}$ Division of Community Health, Faculty of Medicine, Memorial University, St. John's, Newfoundland and Labrador, Canada, ${ }^{3}$ Health Sciences Centre and Division of Laboratory Medicine; Faculty of Medicine, Memorial University, St. John's, Newfoundland and Labrador, Canada, ${ }^{4}$ Public Health Research, Education and Development Program, Kingston, Frontenac and Lennox \& Addington Health Unit, Kingston, Ontario, Canada, ${ }^{5}$ Department of Public Health Sciences, University of Toronto, Toronto, Ontario, Canada, ${ }^{6}$ Provincial Medical Genetics Program, Health Care Corporation of St. John's, St. John's, Newfoundland and Labrador, Canada, ${ }^{7}$ Department of Earth Sciences, University of Waterloo, Waterloo, Ontario, Canada and ${ }^{8}$ London Health Sciences Centre \& Department of Clinical Biochemistry, University of Western Ontario, London, Ontario, Canada

Email: Shiliang Liu - shiliang_liu@hc-sc.gc.ca; Roy West - roywest@mun.ca; Edward Randell - erandell@mun.ca;

Linda Longerich - lindal@mun.ca; Kathleen Steel O'Connor - koconnor@healthunit.on.ca; Helen Scott - helen_scott55@hotmail.com; Marian Crowley - hcc.cromar@hccsj.nf.ca; Angeline Lam - abddoell@ primus.ca; Victor Prabhakaran - victor.prabhakaran@lhsc.on.ca; Catherine McCourt* - Catherine_McCourt@hc-sc.gc.ca

${ }^{*}$ Corresponding author
\end{abstract}

Published: 27 September 2004

BMC Pregnancy and Childbirth 2004, 4:20 doi:10.1 I86/147/-2393-4-20
Received: 13 May 2004

Accepted: 27 September 2004

This article is available from: http://www.biomedcentral.com/I47I-2393/4/20

(c) 2004 Liu et al; licensee BioMed Central Ltd.

This is an open-access article distributed under the terms of the Creative Commons Attribution License (http://creativecommons.org/licenses/by/2.0), which permits unrestricted use, distribution, and reproduction in any medium, provided the original work is properly cited.

\begin{abstract}
Background: Periconceptional use of vitamin supplements containing folic acid reduces the risk of a neural tube defect (NTD). In November 1998, food fortification with folic acid was mandated in Canada, as a public health strategy to increase the folic acid intake of all women of childbearing age. We undertook a comprehensive population based study in Newfoundland to assess the benefits and possible adverse effects of this intervention.

Methods: This study was carried out in women aged 19-44 years and in seniors from November 1997 to March 1998, and from November 2000 to March 200I. The evaluation was comprised of four components: I) Determination of rates of NTDs; II) Dietary assessment; III) Blood analysis; IV) Assessment of knowledge and use of folic acid supplements.

Results: The annual rates of NTDs in Newfoundland varied greatly between 1976 and 1997, with a mean rate of 3.40 per I,000 births. There was no significant change in the average rates between 199I-93 and 1994-97 (relative risk [RR] 1.01, 95\% confidence interval $[\mathrm{Cl}]$ 0.76-I.34). The rates of NTDs fell by $78 \%(95 \% \mathrm{Cl} 65 \%-86 \%)$ after the implementation of folic acid fortification, from an average of 4.36 per I,000 births during I99I-1997 to 0.96 per I,000 births during I998-200I (RR 0.22, $95 \% \mathrm{Cl} 0.14-0.35)$. The average dietary intake of folic acid due to fortification was $70 \mu \mathrm{g} /$ day in women aged $19-44$ years and $74 \mu \mathrm{g} /$ day in seniors. There were significant increases in serum and RBC folate levels for women and seniors after mandatory fortification. Among seniors, there were no significant changes in indices typical of vitamin $B_{12}$ deficiencies, and no evidence of improved folate status masking haematological manifestations of vitamin $B_{12}$ deficiency. The proportion of women aged 19-44 years taking a vitamin supplement containing folic acid increased from $17 \%$ to $28 \%$.
\end{abstract}

Conclusions: Based on these findings, mandatory food fortification in Canada should continue at the current levels. Public education regarding folic acid supplement use by women of childbearing age should also continue. 


\section{Background}

Neural tube defects (NTDs) are birth defects resulting from the failure of neural tube closure during early development of the human embryo. The 1997 Canadian national NTD birth prevalence was 0.75 per 1,000 births (live births and stillbirths), down from 1.16 per 1,000 in 1989 [1]. The rates tend to be higher in the eastern provinces than in the west [2-4]. Historically, Newfoundland has had one of the highest rates in North America with a reported average yearly rate for 1976-1997 of 3.4 per 1,000 births (including live births, stillbirths and fetuses from pregnancies terminated after a prenatal diagnosis of an NTD) [4].

Evidence from a number of studies has demonstrated that periconceptional use of vitamin supplements containing folic acid reduces the risk of NTDs [5-8]. Although the mechanism of action of this nutrient in influencing the risk of NTDs is poorly understood, the evidence of the benefit of folic acid has led many health organizations since late 1992 to recommend periconceptional folic acid supplementation, at a level of $400 \mu \mathrm{g} /$ day for low risk women [9-11].

Because of concern that public education campaigns alone would not be effective in achieving optimal periconceptional folic acid intake for the majority of women, food fortification with folic acid was proposed as a strategy to ensure that all women of childbearing age increase their dietary intake of this vitamin. In November 1998, Health Canada mandated fortification of white flour and enriched pasta and cornmeal with folic acid [12]. Since diets vary, it was known that it would be virtually impossible to fortify food with folic acid at a level that ensures that the target population receives an additional $400 \mu \mathrm{g}$ / day, while protecting the non-targeted population from an undesirably high amount. As a result, conservative levels of fortification were introduced. White flour is fortified with folic acid at a level of $0.15 \mathrm{mg}$ per $100 \mathrm{~g}$ of flour. This intervention was expected to increase the average daily folic acid intake of women of childbearing age by about $100 \mu \mathrm{g}$ [13].

The question of whether folic acid fortification of grain products poses any serious health risk has been controversial. The main concern has been the potential masking of vitamin $B_{12}$ deficiency, a condition that affects $10-15 \%$ of the population over age 60 years $[14,15]$. Increased folic acid intake may correct the haematologic signs of vitamin $\mathrm{B}_{12}$ deficiency, thus delaying diagnosis and treatment of the condition while its attendant neurologic manifestations progress. Seniors may be at particular risk since the incidence of vitamin $B_{12}$ deficiency increases with age.
We therefore undertook a comprehensive population based study to evaluate the effectiveness of the public health strategy of food fortification with folic acid and to determine possible adverse effects resulting from fortification.

\section{Methods Study design}

This evaluative study was designed as a population based study and included four components as follows: I) Determination of rates of NTDs; II) Dietary assessment; III) Blood analysis; IV) Assessment of knowledge and use of folic acid supplements. The latter three components of the study were carried out in two phases; the first phase took place prior to the introduction of mandatory fortification, from November 1997 to March 1998 and the second phase occurred from November 2000 to March 2001, after two years of implementation of mandatory fortification.

This study was undertaken in Newfoundland because of the historically high rates of NTDs in the province, and because of strong interest in the health community in this initiative. Newfoundland and Labrador, with a population of approximately 500,000, has about 5,000 births annually. An urban (St. John's) and rural (Clarenville, Port Blandford, Random Island area) location in the province were chosen as the sites for this study. Data collected from these sites were compared between Phase I (November 1997 to March 1998) and Phase II (November 2000 to March 2001). Table 1 shows schematically the framework including objectives and sampling of subjects for this study. As part of this project, dietary assessment, blood analysis and assessment of knowledge and use of supplements were also carried out in a 2-phase population based study of women of reproductive age in Kingston, Ontario and environs. The results of this study will be reported elsewhere.

\section{Data collection}

In order to examine temporal changes in the rates of NTDs in Newfoundland, data were compiled from the Newfoundland and Labrador Medical Genetics Program from 1976 to 2001. This Program ascertains cases of NTDs annually and maintains an NTD database. The database has recorded cases of NTD since 1976. Cases are identified in the following ways: provincial live birth and stillbirth notification forms, maternal-fetal medicine referrals (only one tertiary care unit in the province), and letters sent to all medical records departments of all provincial hospitals requesting data on cases assigned ICD-9/10 codes associated with NTDs or terminations for NTDs. These multiple sources are utilized to ensure complete ascertainment. NTD cases include anencephaly, spina bifida and encephalocele diagnosed in live births, stillbirths (a gestational 
Table I: Framework for a two phase, multi site study to examine the effects of food fortification with folic acid

\begin{tabular}{|c|c|c|c|}
\hline Content & Study objective & Sample ** & Location \\
\hline I. Rates of NTDs & $\begin{array}{l}\text { Determine rate of NTD-affected pregnancies, } \\
\text { pre and post fortification }\end{array}$ & Newfoundland population & Newfoundland \\
\hline II. Dietary assessment** & $\begin{array}{l}\text { Determine dietary intake of folate, pre and post } \\
\text { Fortification }\end{array}$ & $\begin{array}{l}\text { A) Non-pregnant women of childbearing age } \\
\text { (19-44 years), not taking supplements } \\
\text { containing folic acid; }\end{array}$ & $\begin{array}{l}\text { St. John's, Rural } \\
\text { Newfoundland }\end{array}$ \\
\hline III. Blood analysis* & $\begin{array}{l}\text { Determine blood folate and vitamin } B_{12} \text { status, } \\
\text { pre and post fortification }\end{array}$ & $\begin{array}{l}\text { B) Seniors ( } 65 \text { years or older) not taking } \\
\text { supplements containing folic acid or } B_{12} \\
\text { supplement and not diagnosed with anaemia. }\end{array}$ & $\begin{array}{l}\text { St. John's, Rural } \\
\text { Newfoundland }\end{array}$ \\
\hline $\begin{array}{l}\text { IV. Knowledge and intake } \\
\text { of folic acid supplements }\end{array}$ & $\begin{array}{l}\text { Determine knowledge and consumption of folic } \\
\text { acid supplements, pre and post fortification }\end{array}$ & $\begin{array}{l}\text { Non-pregnant women of childbearing age (19- } \\
44 \text { years) }\end{array}$ & $\begin{array}{l}\text { St. John's, Rural } \\
\text { Newfoundland }\end{array}$ \\
\hline
\end{tabular}

* The same sample of women and seniors are analyzed in Components II and III.

** Sampling was done separately for Phases I and II.

age of 20 weeks and above or birthweight of $500 \mathrm{~g}$ and above) and fetuses from pregnancies terminated (at any gestational age) after a prenatal diagnosis of an NTD.

For the knowledge assessment component of the study, women between the ages of 19 and 44 years were recruited through a random telephone survey. In the initial telephone survey, women were asked about their use of vitamin supplements and knowledge of the importance of folic acid for reducing the risk of NTDs or for fetal development. Women who completed the initial telephone survey were subsequently screened for their eligibility for dietary and blood assessments. Women who were not taking supplements containing folic acid and not pregnant were eligible to participate. This sampling procedure for Phase I and Phase II resulted in a response rate of $59.7 \%$ and $65.4 \%$, respectively, with no difference between urban and rural response rates. A total of 233 women were recruited into Phase I and 204 women were recruited in Phase II, who completed components II, III and IV of the study.

Seniors were recruited in the same manner as the samples of women, but were drawn only from St. John's, Newfoundland. Seniors aged 65 years or over, not diagnosed with vitamin $B_{12}$ deficiency or anaemia and not taking vitamin $B_{12}$ or supplements containing folic acid, were eligible for dietary and blood sample assessments. A total of 202 seniors were recruited in Phase I and 186 were recruited in Phase II (response rate $45.1 \%$ and $44.9 \%$, respectively).

In order to determine intakes of naturally occurring folate (the form of the vitamin found naturally in foods) pre and post fortification, and dietary intakes of folic acid (the synthetic form of the vitamin) post fortification, a Willett food frequency dietary questionnaire [16] was administered to subjects during an in-person interview. There were some modifications to the questionnaire to include common Newfoundland foods and to ensure that all foods high in folate were included. The dietary questionnaire was used to estimate an average frequency of consumption of 124 food items over the previous period of one year.

The women and senior participants were also asked to provide a sample of blood in order to determine blood folate and vitamin $\mathrm{B}_{12}$ status in Phase I and Phase II. Laboratory tests for complete blood count (CBC), red blood cell (RBC) folate, serum folate, creatinine, vitamin $B_{12}$ plasma homocysteine (HCY) and methylmalonic acid (MMA) were conducted at the laboratories of the Health Care Corporation of St. John's.

\section{Data analysis}

Rate of NTDs was defined as the number of above described NTD cases, divided by the total number of live births, stillbirths, and pregnancy terminations for an NTD (termed as "births" hereafter). First we examined the temporal trend in annual rates of NTDs from 1976 to 2001 using 3-year moving average rates, then we focused on comparison of the NTD data for the most recent 11 years, identified as pre-supplementation (1991-1993), pre-fortification (1994-1997) and post-fortification (19982001). We regard the year 1997 as a transition period, or partial fortification period, since fortification of white flour and enriched pasta and cornmeal was permitted in Canada as of December 1996 [17]. Thus we also analysed the NTD data using 1994-1996 as a pre-fortification period.

Mean daily intakes of naturally occurring folate were calculated for women aged 19-44 years and for seniors in Phase I and Phase II. Also, for Phase II, average daily intakes of folic acid from fortified foods were calculated. 


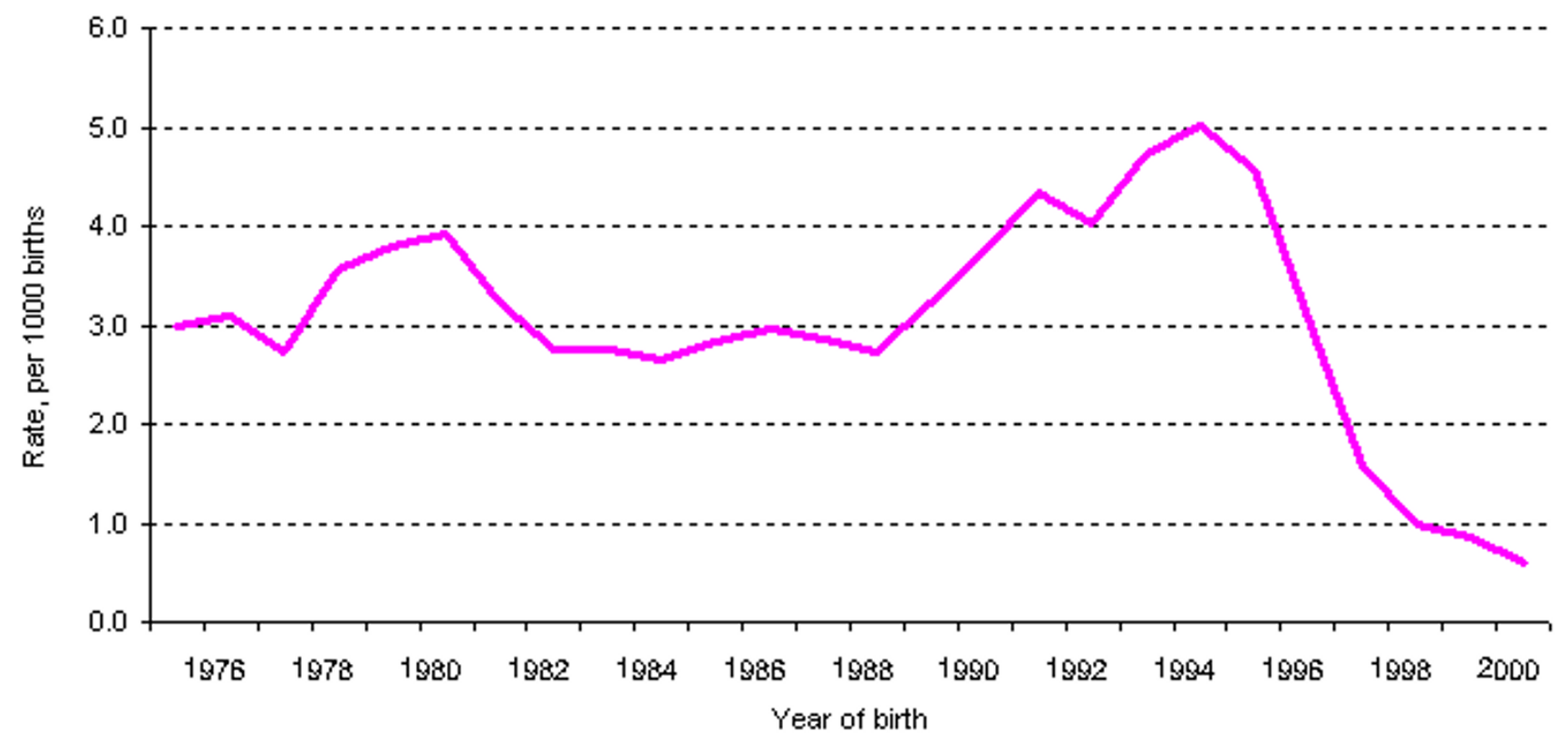

\section{Figure I}

Rates of NTDs in Newfoundland and Labrador, 1976 to 200 I (3-year moving average rates) $*$ The rate for 1976 is a 2-yr average based on data for 1976 and 1977 and the rate for $200 \mathrm{I}$ is a 2-yr average based on data for 2000 and $200 \mathrm{I}$.

Data from the blood analyses were tested for normality with the Komogorov-Smirnov test, and differences between groups were tested using the non-parametric Mann-Whitney U test. The distributions of plasma MMA, plasma HCY, serum folate, RBC folate and serum vitamin $\mathrm{B}_{12}$ were skewed. Values were therefore log transformed to give an approximate normal distribution for estimation of geometric mean and confidence intervals. Unless otherwise stated, all laboratory values presented in this paper are geometric means and 95\% confidence intervals (CI). Differences in the frequency of high or low results based on reference values were tested by Pearson chi-square statistics.

All data for this study were entered into SPSS (the Statistical Package for Social Sciences) Rel. 10.0 after the end of each phase. Data from the dietary interviews were analyzed using Epi-Info (Version 6.04d), while the laboratory data and the data about knowledge and use of supplements were analyzed using SPSS.

\section{Results \\ I. Rate of NTDs}

There were 617 ascertained cases of NTD among live births, stillbirths and pregnancies terminated for an NTD in Newfoundland over the 26 year period. The annual rates of NTDs in the province varied greatly over time, with the lowest rate of 2.18 per 1,000 births in 1989, and the highest rate of 5.92 per 1,000 births in 1995. The average rate of NTDs between 1976 and 1997 was 3.40 per 1,000 births. A dramatic drop is seen in 1997, in which the rate of NTDs was 2.20 per 1,000 births, down from 5.49 per 1,000 births in the previous year. The decreasing trend continued after 1998 (Figure 1 shows 3-year moving average rates).

The NTD data for the years 1991-2001 are presented in three periods in Table 2. The mean annual rates were 4.35 per 1,000 births during 1991-1993 and 5.02 per 1,000 births during 1994-1996 (1994-96 vs 1991-93, relative risk [RR] 1.15, 95\% CI 0.86-1.54, $\mathrm{p}=0.95)$, and 4.37 per 1,000 births during 1994-1997 (1994-97 vs 1991-93, RR 1.01, 95\% CI 0.76-1.34, p = 0.54).

The total annual rate of NTDs fell by $78 \%$ after the implementation of folic acid fortification, from an average of 4.36 per 1,000 births during $1991-1997$ to 0.96 per 1,000 births during 1998-2001 (RR 0.22, 95\% CI 0.14-0.35, p $<0.0001)$. It is worthwhile to note that there has been no significant increase in the proportion of NTDs from terminated pregnancies since 1994 . 
Table 2: Annual rates of neural tube defects (NTDs) in Newfoundland and Labrador before folic acid supplementation (199 I-1993), prior to folic acid fortification (1994-1997) and after fortification (1998-200I)

\begin{tabular}{|c|c|c|c|c|c|}
\hline \multirow[t]{2}{*}{ Period } & \multicolumn{3}{|c|}{ No. of cases of NTDs } & \multirow[t]{2}{*}{ Total no. of births* } & \multirow[t]{2}{*}{ Rate per 1,000 births } \\
\hline & $\begin{array}{l}\text { In live births and } \\
\text { stillbirths }\end{array}$ & $\begin{array}{l}\text { In terminated } \\
\text { pregnancies }\end{array}$ & Total & & \\
\hline \multicolumn{6}{|c|}{ Pre-supplementation } \\
\hline $1991-1993$ & 50 & 40 & 90 & 20,711 & 4.35 \\
\hline \multicolumn{6}{|c|}{ Pre-fortification } \\
\hline $1994-1997$ & 53 & 50 & 103 & 23,592 & 4.37 \\
\hline \multicolumn{6}{|c|}{ Post-fortification } \\
\hline |998-200| & 8 & 11 & 19 & 19,816 & 0.96 \\
\hline
\end{tabular}

* The total number of births includes live births, stillbirths and terminations for an NTD.

\section{Dietary Assessment}

There was no statistically significant change in the average daily intake of naturally occurring folate among either women aged 19-44 years or seniors between Phase I and Phase II ( $\mathrm{p}=0.19$ and $\mathrm{p}=0.18$, respectively). Seniors generally had dietary folate intake slightly higher than women of childbearing age. In Phase I, the average daily intake of naturally occurring folate was $306 \mu \mathrm{g} /$ day for seniors and $262 \mu \mathrm{g} /$ day for women aged 19-44 years, while in Phase II, the average daily intake of naturally occurring folate was $290 \mu \mathrm{g} /$ day for seniors and $248 \mu \mathrm{g} /$ day for women aged 19-44 years.

The implementation of mandatory fortification resulted in an average additional dietary intake of $70 \mu \mathrm{g} /$ day of folic acid in women aged 19-44, and $74 \mu \mathrm{g} /$ day of folic acid among seniors. It is noteworthy that for the women the average daily folic acid intake due to food fortification was less than the approximately $100 \mu \mathrm{g}$ that was previously predicted for women of childbearing age. The maximum dietary intake of folic acid due to fortification for an individual woman was $235 \mu \mathrm{g} / \mathrm{day}$, and for an individual senior was $219 \mu \mathrm{g} /$ day.

\section{Blood Analysis}

Serum folate and RBC folate increased significantly from Phase I to Phase II in both women aged 19-44 years and seniors $(\mathrm{p}<0.001)$. For both age groups, there was a corresponding decrease in mean plasma HCY levels (Tables 3 and 4$)$. The prevalence of low serum folate $(\leq 6.8 \mathrm{nmol} / \mathrm{L})$ was eliminated from the sample of seniors and the proportion of elderly participants with low stores as indicated by $\mathrm{RBC}$ folate levels $(<373 \mathrm{nmol} / \mathrm{L}$ ) was reduced from $2.5 \%$ to $1.6 \%$. The proportion of women aged $19-44$ years with high $\mathrm{HCY}(>13.2 \mu \mathrm{mol} / \mathrm{L})$ also decreased from $15.9 \%$ to $7.6 \%(\mathrm{p}=0.002)$ (data not shown).

There was a significant increase in mean vitamin $\mathrm{B}_{12}$ levels in women aged 19-44 and seniors ( $\mathrm{p}=0.020$ and $\mathrm{p}<$ 0.001 , respectively, Tables 3 and 4 ). The proportion of seniors with low vitamin $\mathrm{B}_{12}(<133 \mathrm{pmol} / \mathrm{L})$ was $18.8 \%$ prior to fortification and following fortification this proportion declined to $11.8 \%(\mathrm{p}=0.032)$ (data not shown). A statistically significant increase in mean plasma MMA levels was observed in women subjects $(\mathrm{p}=0.008)$ but not in seniors ( $p=0.229)$ (Tables 3 and 4$)$. There was also an increase in the proportion of women aged 19-44 years with MMA values above the upper reference value of 0.37 $\mu \mathrm{mol} / \mathrm{L}$ from $3.6 \%$ in Phase I to $14.9 \%$ in Phase II ( $\mathrm{p}<$ $0.001)$. There was no significant change in the proportion of abnormal MMA values in seniors. Moreover, among seniors, blood analysis showed no significant difference

Table 3: Laboratory data (geometric mean and $95 \%$ confidence interval) for young women participants (age I9-44 years) in Phase I and Phase II

\begin{tabular}{|c|c|c|c|}
\hline Characteristic & Phase I & Phase II & $P$ value ${ }^{\dagger}$ \\
\hline Total participants (n) & 233 & 204 & \\
\hline Serum folate (nmol/L) & $13.5(12.9-\mid 4.1)$ & $18.1(17.3-18.9)$ & $<0.001$ \\
\hline RBC folate (mol/L) & $625(601-649)$ & $818(784-854)$ & $<0.001$ \\
\hline Plasma HCY $(\mu \mathrm{mol} / \mathrm{L})$ & $10.2(9.8-10.7)$ & $9.2(8.8-9.6)$ & 0.001 \\
\hline Serum vitamin $B_{12}(p m o l / L)$ & $177(169-186)$ & $200(190-211)$ & 0.02 \\
\hline Plasma MMA ( $\mu \mathrm{mol} / \mathrm{L})$ & $0.18(0.17-0.19)$ & $0.21(0.19-0.22)$ & 0.008 \\
\hline
\end{tabular}

† $P$ value for the difference between Phase I and Phase II is based on a non-parametric Mann-Whitney $U$ test. RBC denotes red blood cell, HCY denotes homocysteine, and MMA refers to methylmalonic acid. 
Table 4: Laboratory data (geometric mean and $95 \%$ confidence interval) for senior participants (age 65 years or over) between Phase I and Phase II

\begin{tabular}{|c|c|c|c|}
\hline Characteristic & Phase I & Phase II & $P$ value $\ddagger$ \\
\hline Total participants (n) & 202 & 186 & \\
\hline Serum folate (nmol/L) & $14.8(\mid 4.0-15.6)$ & $23.0(22.0-24.1)$ & $<0.001$ \\
\hline RBC folate $(\mathrm{mol} / \mathrm{L})$ & $745(7 / 3-779)$ & $916(873-961)^{\dagger}$ & $<0.001$ \\
\hline Plasma HCY $(\mu \mathrm{mol} / \mathrm{L})$ & $13.6(13.0-14.2)^{\dagger}$ & $12.3(11.7-12.9)^{\dagger}$ & 0.001 \\
\hline Serum vitamin $B_{12}(p m o l / L)$ & $183(173-194)$ & $216(202-231)$ & $<0.001$ \\
\hline Plasma MMA $(\mu \mathrm{mol} / \mathrm{L})$ & $0.24(0.22-0.27)^{\dagger}$ & $0.26(0.24-0.28)$ & 0.229 \\
\hline
\end{tabular}

† The Komogorov-Smirnov test showed that the log transformed data were non-normal $(p<0.05)$.

$\ddagger P$ value for the difference between Phase I and Phase II is based on a non-parametric Mann-Whitney $U$ test.

RBC denotes red blood cell, HCY denotes homocysteine and MMA refers to methylmalonic acid.

in mean haemoglobin concentrations, mean corpuscular volume (MCV), or proportion with abnormally high $\mathrm{MCV}$ ( $>99 \mathrm{fL}$ ) or low haemoglobin $(<120 \mathrm{~g} / \mathrm{L})$ concentrations.

\section{Knowledge and use of folic acid supplements}

There was a significant increase from Phase I to Phase II in the proportion of women aged 19-44 years who knew the importance of folic acid (from 33\% to 46\%, p < 0.001 ). The proportion of women taking a vitamin supplement containing folic acid increased substantially between the two time periods (from $17 \%$ to $28 \%$, p < 0.003 ). Information about folic acid dosage was not collected.

\section{Discussion}

The results of a number of studies have led to the conclusion that periconceptional folic acid supplementation reduces the risk of NTDs [5-8]. Among the responses to this research evidence were calls in the early 1990s for mandatory fortification of food with folic acid. It was argued that this public health intervention would address concerns about achieving population level compliance with recommendations to women to take vitamin supplements containing folic acid before becoming pregnant and in the first weeks of pregnancy. These concerns were borne out in several Canadian studies suggesting that many caregivers $[18,19]$ and women $[20,21]$ remained unaware of the relationship between folic acid and NTDs. More recent studies have shown an increase in knowledge about folic acid, but supplementation rates remain low [22-25].

In March 1996 the US Food and Drug Administration (FDA) announced that it would permit addition of folic acid to enriched flour and other enriched cereal grain products, and that this addition would be mandatory as of January 1998. The level of fortification was set at $0.14 \mathrm{mg}$ folic acid per $100 \mathrm{~g}$ of cereal grain product. It was determined that at this level of fortification, the intake of folate (from all sources) for the target and the general population would be kept below $1,000 \mu \mathrm{g} /$ day, which was deemed to be the safe upper limit. This level of fortification was estimated to increase the average daily intake of folic acid in women of childbearing age by about $100 \mu \mathrm{g}$ [26]. Subsequent to the US decision, Canada followed suit, permitting folic acid fortification at an equivalent level in December 1996 (addition of folic acid to white flour and enriched pasta and cornmeal at $0.15 \mathrm{mg}$ folic acid per $100 \mathrm{~g}$ of flour and $0.20 \mathrm{mg}$ folic acid per 100 $\mathrm{g}$ of pasta). In Canada, fortification became mandatory in November 1998.

\section{Rate of NTDs}

Our results show a highly significant drop in the rate of NTDs in Newfoundland, taking into account all identified affected pregnancies (live births, stillbirths and pregnancies terminated after a prenatal diagnosis of an NTD). The $78 \%$ (95\% CI 65\%-86\%) reduction in the NTD rate after implementation of fortification is greater than the $18 \%-$ $22 \%$ reduction predicted at current levels of fortification $[27,28]$, and greater than the $19 \%$ reduction in birth prevalence of NTDs reported in the US after mandatory fortification [29]. The results in Newfoundland are closer to the $54 \%$ reduction $(95 \%$ CI $34 \%-68 \%$ ) in rate of NTDs reported in Nova Scotia after fortification [2]. De Wals et al. observed a $32 \%$ reduction (95\% CI $23 \%-41 \%)$ in NTDs in Quebec between 1992-97 and 1998-2000 [30]. Ray et al. [31] analyzed maternal serum screening data for Ontario and observed a decline in NTD prevalence from 1.13 per 1,000 pregnancies before fortification to 0.58 per 1,000 pregnancies thereafter (prevalence ratio $0.52,95 \%$ CI 0.40-0.67).

The large reduction in the rate of NTDs in Newfoundland may be due, at least in part, to the fact that Newfoundland had higher background rates of NTDs. This population may be more sensitive to the influence of folic acid. In a large-scale public health campaign in northern and southern China, periconceptional use of $400 \mu \mathrm{g} /$ day folic acid 
supplements was associated with a reduction in NTD risk of $79 \%$ for women in northern China, where the baseline NTD rate was high and similar to that observed in Newfoundland. A lower risk reduction of $41 \%$ was observed in the southern region where the pre-campaign NTD rate was much lower [32].

The $65 \%$ increase in the proportion of women taking vitamin supplements containing folic acid, from $17 \%$ in Phase I to $28 \%$ in Phase II, suggests that an increasing trend in folic acid supplementation may have played a role in the declining NTD rate in Newfoundland. In this study it was not possible to determine the individual contribution of supplementation and fortification to the trend in NTDs.

The annual rate of NTDs in the pre-fortification period (1994-97) did not differ significantly from that of the pre-supplementation period (1991-93); this is true whether 1997 is excluded or included in the pre-fortification period. The increase in the rates of NTDs in 1995 and 1996 appears random and largely unexplainable. The changes in the NTD rates between 1994-1996 and 19911993 and between 1995-1997 and 1991-1993 were not statistically significant. In addition, our data do not show an obvious increase in the proportion of NTDs in terminated pregnancies during 1994 and 1996 (data available upon request).

\section{Dietary intakes and blood folate levels}

The questionnaire used in this dietary assessment was a modified Willett questionnaire [16], administered in a face-to-face interview with trained personnel. The Willett food frequency dietary questionnaire has been well validated [33] and proved easy to administer for this sample population.

The daily intake of naturally occurring folate among women aged 19-44 years in this study (average $248 \mu \mathrm{g} /$ day in the Phase II sample) was similar to values found in other studies of women's diet [34,35]. For seniors in Phase II, naturally occurring folate in the diet averaged $290 \mu \mathrm{g} /$ day which was comparable to values found for persons age 49 and older in an Australian study [36]. The dietary folic acid intake due to fortification did not exceed the Tolerable Upper Intake Level (UL) of 1,000 $\mu \mathrm{g}$ folic acid/day [14] for any of the participants (this UL for folic acid does not include naturally occurring folate). It is important to note that this part of the study excluded persons taking vitamin supplements containing folic acid. While it was not possible to estimate the proportion of people in the general Newfoundland population who may be consuming more than $1,000 \mu \mathrm{g} /$ day of folic acid from fortification and supplementation combined, it is likely that this proportion is small. The average dietary intake and maximum intake of folic acid due to fortification were $70 \mu \mathrm{g} /$ day and $235 \mu \mathrm{g} /$ day, respectively, for women aged 19-44 years, and $74 \mu \mathrm{g} /$ day and $219 \mu \mathrm{g} /$ day, respectively, for seniors. The average folic acid dose in folic acid containing over-the-counter supplements marketed in Canada is about $350 \mu \mathrm{g} /$ day (Health Canada unpublished information).

The results of this study provide strong evidence of improved blood folate status in women aged 19-44 years following mandatory fortification with folic acid. Women showed evidence of increased levels of serum and RBC folate and decreased levels of plasma HCY. These results are consistent with an earlier study examining the effect of fortification in the Framingham offspring study cohort [37].

Mandatory food fortification with folic acid has resulted in improvements in folate indices in seniors. Both mean serum folate and mean RBC folate increased following folic acid fortification (55\% and 23\%, respectively, Table 4 ). Consistent with this was a moderate decrease in mean plasma HCY levels among seniors by $1.3 \mu \mathrm{mol} / \mathrm{L}$. Fortification of food with folic acid and an upward shift in blood folate levels is of benefit to the elderly population especially with regard to risk of cardiovascular disease. High levels of homocysteine are associated with both cerebrovascular and coronary heart disease [38-40].

\section{Vitamin $B_{12}$ status}

There was a decline in the proportion of seniors with low vitamin $B_{12}$ levels, and there was actually a slight increase in mean vitamin $B_{12}$ levels. In vitamin $B_{12}$ deficiency, plasma MMA is usually elevated. Plasma MMA is believed to be a better indicator of vitamin $B_{12}$ status at the tissue level than serum vitamin $B_{12}$ levels are. Our study showed no change in mean MMA levels nor increased proportion of elderly with high levels. In addition, there was no change in the indicators of anaemia (i.e., haemoglobin and MCV) in seniors post fortification in our study. Thus, these results show no evidence of a deterioration in vitamin $B_{12}$ status among seniors. Furthermore, there is no evidence of improved folate status resulting in masking of the haematological manifestations of vitamin $\mathrm{B}_{12}$ deficiency among seniors as a group. There was no evidence of deteriorating vitamin $\mathrm{B}_{12}$ status among young women participants based on vitamin $\mathrm{B}_{12}$ measurements. The upward trend in plasma MMA levels and higher proportion of abnormal values among young women is being further evaluated. It is unlikely that this is a direct effect of folic acid fortification and this observation is not consistent with any known effects of folic acid on vitamin $B_{12}$ status. 


\section{Limitations}

We have documented the rate of NTDs among live births, stillbirths and terminated pregnancies known to have an NTD. It was not possible to include NTDs that may have occurred in pregnancies that resulted in a spontaneous abortion or a termination that occurred for reasons other than a congenital anomaly.

This study, and other studies of fortification in Canada, are limited by the fact that there was no precise date when exposure to food fortified with folic acid began. The addition of folic acid to white flour and enriched pasta and cornmeal was permitted as of December 1996. Industry was switching to folic acid-containing enrichment premixes, especially towards the end of 1997, in anticipation of both US requirements for fortification as of January 1,1998, and Canadian plans to implement mandatory fortification. Although this requirement did not come into force in Canada until late 1998, the Phase I (November 1997 to March 1998) subjects of our study may have consumed at least some food fortified with folic acid. This would result in an underestimate of improvements in blood folate status due to fortification, and might lead us to miss adverse effects on vitamin $B_{12}$ status. On the other hand, the fact that we observed such marked improvements in blood folate status leads us to conclude that there was a real increase in exposure to folic acid through fortification, over the study period.

Another limitation of this study is the possible underestimation of folic acid intake due to fortification. Our calculations were based on the assumption that manufacturers are fortifying flour at the required level. It has been suggested that allowance for "overages" is resulting in higher amounts in the affected products [41]. Also, for enriched pasta, the required level of fortification is from a minimum of $0.20 \mathrm{mg} / 100 \mathrm{~g}$ pasta to a maximum of $0.27 \mathrm{mg} /$ $100 \mathrm{~g}$. In our calculations we assumed the minimum level of fortification.

We initially selected a random sample of subjects through random digit dialling, and asked eligible respondents for voluntary participation in the study. The reasonable level of response for the dietary questionnaire and blood sampling among rural and urban women aged 19-44 years suggests that with caution, we can generalize the results to all Newfoundland women of childbearing age. However, these findings may not be representative of the rest of Canada because of population differences in factors such as genetic background and dietary behaviour. These differences may also affect the generalizability of the NTD trend.

The sample response rate for the dietary questionnaire and blood sampling in seniors was approximately $45 \%$ both in Phase I and in Phase II. Many of the refusals to participate were due to illness of the eligible person. Furthermore, seniors residing in long term care settings were not included. Thus our sample population of seniors may be healthier than the general population age 65 and over in the province.

\section{Conclusions}

The implementation of food fortification with folic acid has been accompanied by a marked decrease (78\%) in the rate of NTDs in Newfoundland. The blood folate status of women aged 19-44 years improved following mandatory fortification. There is no evidence of adverse effects of the current levels of fortification on individuals aged 65 years and older. Specifically, there is no evidence to suggest an adverse effect of folic acid fortification on detection of abnormalities in vitamin $\mathrm{B}_{12}$ status based on biochemical and haematological indices.

Based on these findings, mandatory food fortification with folic acid should continue in Canada at the current levels. Over the time period of this study, the proportion of women aged 19-44 years taking a vitamin supplement containing folic acid increased. It was not possible to determine the magnitude of the separate contributions of fortification and supplementation to the decline in NTDs. Therefore, we recommend that public health efforts to promote awareness of the importance of folic acid supplementation among women of childbearing age continue. Ongoing surveillance of NTDs in Newfoundland and other parts of Canada is necessary to determine if the decline in NTD rate is maintained, and to enable further evaluation of prevention strategies. National surveillance of congenital anomalies including NTDs is a critical public health function that should be strengthened where necessary.

We look forward to the results of a current epidemiologic study, funded by the Canadian Institutes of Health Research (CIHR), of NTDs in 7 Canadian provinces between 1993 and 2002. There is also research into the relationship between increased folic acid consumption and reduced risk of other congenital anomalies, cardiovascular disease and cancer [42-45]. As this body of knowledge grows, public health practitioners and regulators in Canada and internationally will have more evidence with which to refine existing disease prevention policies and develop new ones.

\section{Competing interests}

The authors declare that they have no competing interests.

\section{List of abbreviations}

$\mathrm{CBC}$, complete blood count 


\section{CI, confidence interval}

CIHR, Canadian Institutes of Health Research

FDA, Food and Drug Administration

HCY, homocysteine

$\mathrm{MCV}$, mean corpuscular volume

MMA, methylmalonic acid

NTD, neural tube defect

RBC, red blood cell

SPSS, Statistical Package for Social Sciences

\section{Authors' contributions}

SL and CM oversaw the whole study and drafted the manuscript. SL carried out the analysis of NTD rate and statistical analysis. RW, LL, KSO and HS designed the study and carried out the data collection and the dietary assessment ER, AL and VP participated in the design and carried out the blood analysis. MC carried out the collection of NTD data. All authors read, revised and approved the final manuscript.

\section{Acknowledgements}

This study was funded by Health Canada's Health Surveillance and Epidemiology Division. This study was granted full ethics approval by Research Ethics Boards at Memorial University of Newfoundland and at Queen's University. All study subjects gave written informed consent prior to participation in this study.

We particularly thank Linda Turner for her earlier work on this study. We gratefully acknowledge the support and assistance of many individuals for their participation in this study, including the interviewers, laboratory and clinical support staff, and data entry and analysis staff. Particular thanks to Vicki Gill, project coordinator in Newfoundland, Millie Trask, for help with data entry and word processing in the laboratory component of the study, and Ernesto Delgado, for his logistical support within Health Canada.

\section{References}

I. Health Canada: Canadian Perinatal Health Report 2000. Ottawa: Minister of Public Works and Government Services Canada 2000.

2. Persad VL, Van den Hof MC, Dubé JM, Zimmer P: Incidence of open neural tube defects in Nova Scotia after folic acid fortification. CMAJ 2002, I 67:24I-245.

3. Gucciardi E, Pietrusiak A, Reynolds DL, Rouleau J: Incidence of neural tube defects in Ontario, I986-I999. CMAJ 2002, I 67:237-240.

4. Crane JMG, Sun C, Hutchens D, Crowley M: The epidemiology of neural tube defects in Newfoundland and Labrador. J Soc Obstet Gynaecol Can 200I, 23:5 I0-5I4.

5. Laurence KM, James N, Miller MH, Tennant GB, Campbell H: Double-blinded randomized controlled trial of folate treatment before conception to prevent recurrence of neural tube defects. Br Med J (Clin Res Ed) I98I, 282:I509-I5I I.

6. Smithells RW, Nevin NC, Seller MJ, Sheppard S, Harris R, Read AP, Fielding DW, Walker S, Schorah CJ, Wild J: Further experience of vitamin supplementation for prevention of neural tube defect recurrences. Lancet 1983, I:1027-1031.

7. MRC Vitamin Study Research Group: Prevention of neural tube defects: results of the Medical Research Council Vitamin Study. Lancet 1991, 338:131-137.

8. Czeizel AE, Dudas I: Prevention of the first occurrence of neural tube defects by periconceptional vitamin supplementation. N Engl J Med 1992, 327: I832-I835.

9. Recommendations for the use of folic acid to reduce the number of cases of spina bifida and other neural tube defects. MMWR Recomm Rep 1992, 41:1-7.

10. Health Canada: Folic acid: the vitamin that helps protect against neural tube (birth) defects. . Issues April 9,1993

II. Canadian Task Force on the Periodic Health Examination: Periodic health examination, 1994 update: 3. Primary and secondary prevention of neural tube defects. CMAJ 1994, I 5 I: I59- I66.

12. Canada Gazette Part II: Regulatory impact analysis statement, SOR/98-550. 1998, I32(24):3029-3033.

13. Turner LA, McCourt C: Folic acid fortification: What does it mean for patients and physicians? CMAJ I998, I 58:773-774.

14. Institute of Medicine: Folate. In: Dietary reference intakes for Thiamin, Riboflavin, Niacin, Vitamin B6, Folate, Vitamin BI 2, Pantothenic Acid, Biotin, and Choline National Academy Press, Washington, DC; 1998: 196-305.

15. Balk HW, Russell RM: Vitamin $\mathbf{B}_{12}$ deficiency in the elderly. Annu Rev Nutr 1999, I 9:357-377.

16. Willett WC, Reynolds RD, Cottrell-Hoehner S, Sampson L, Browne ML: Validation of a semi-quantitative food frequency questionnaire: Comparison with a I-year diet record. J Am Diet Assoc 1987, 87:43-47.

17. Canada Gazette Part II: Food and drug regulations - amendment SOR/96-527. 1996, I30(26):3318-3320.

18. Perelman V, Singal N, Einarson A, Kennedy D, Koren G: Knowledge and practice by Canadian family physicians regarding periconceptional folic acid supplementation for the prevention of neural tube defects. Can J Clin Pharmacol 1996, 3:|45-I48.

19. Jacobson S, McArthur C, Joshi P, Forman R, Koren G: Availability of folic acid and knowledge about prophylactic use: a survey of urban pharmacies. In: Folic acid and the prevention of neural tube defects Edited by: Koren G. Toronto: Motherisk Program; 1995:|15I-I54.

20. Forman R, Singal N, Perelman V, Chou S, Hoffman L, Parkin P, Koren $G$ : Folic acid and prevention of neural tube defects: a study of Canadian mothers of infants with spina bifida. Clin Invest Med 1996, 19:195-201.

21. Fraser FC: Folic acid and neural tube defects. CMA] I995, I 52:1380-1381.

22. Bonin MM, Bretzlaff JA, Therrien SA, Rowe BH: Knowledge of periconceptional folic acid for the prevention of neural tube defects. The missing links. Arch Fam Med 1998, 7:438-442.

23. Neimanis IM, Paterson JM, Bain E: Preventing neural tube defects - survey of preconceptional use of folic acid. Can Fam Physician 1999, 45: I717-1722.

24. House JD, March SB, Ratnam S, Ives E, Brosnan JT, Friel JK: Folate and vitamin $B_{12}$ status of women in Newfoundland at their first prenatal visit. CMAJ 2000, I 62:1557-I559.

25. Morin VI, Mondor M, Wilson RD: Knowledge on periconceptional use of folic acid in women of British Columbia. Fetal Diagn Ther 2001, 16:1 II-II5.

26. Food and Drug Administration: Food standards: amendment of standards of identity for enriched grain products to require addition of folic acid. Federal Register 1996, 6 I:878I-8797.

27. Wald NJ, Law M, Jordan R: Folic acid food fortification to prevent neural tube defects (letter). Lancet 1998, 35 I:834.

28. Daly S, Mills JL, Molloy A, Conley M, Lee YJ, Kirke PN, Weir DG, Scott JM: Minimum effective dose of folic acid for food fortification to prevent neural-tube defects. Lancet 1997, 350:1666-1669.

29. Honein MA, Paulozzi LJ, Mathews TJ, Erickson JD, Wong LY: Impact of folic acid fortification of the US food supply on the occurrence of neural tube defects. JAMA 200I, 285:298I-2986.

30. De Wals P, Rusen ID, Lee NS, Morin P, Niyonsenga T: Trend in prevalence of neural tube defects in Quebec. Birth Defects Res (Part A) 2003, 67:919-923.

31. Ray JG, Meier C, Vermeulen MJ, Boss S, Wyatt PR, Cole DE: Association of neural tube defects and folic acid food fortification in Canada. Lancet 2002, 360:2047-2048. 
32. Berry RJ, Li Z, Erickson JD, Li S, Moore CA, Wang H: Prevention of neural-tube defects with folic acid in China. N EnglJ Med I999, 34I: I 485-I490.

33. Willett WC, Sampson L, Browne ML, Stamphar MJ, Rosner B, Hennekens $\mathrm{CH}$, Speizer FE: The use of a self-administered questionnaire to assess diet four years in the past. Am J Epidemiol 1988, 127:188-199.

34. Wild J, Seller MJ, Schorah CJ, Smithells RW: Investigation of folate intake and metabolism in women who have had two pregnancies complicated by neural tube defects. Br J Obstet Gynaecol 1994, 101:197-202.

35. de Bree A, van Duseldorp M, Brouwer IA, van het Hof KH, SteegersTheunissen RP: Folate intake in Europe: recommended, actual and desired intake. Eur J Clin Nutr 1997, 5 I:643-660.

36. Flood VM, Webb KL, Smith W, Mitchell P, Bantick JM, Macintyre R, Sindhusake D, Rubin GL: Folate fortification: potential impact on folate intake in an older population. Eur J Clin Nutr 200I, 55:793-800.

37. Jacques PF, Selhub J, Bostom AG, Wilson PW, Rosenberg IH: The effect of folic acid fortification on plasma folate and total homocysteine concentrations. N Engl Med 1999, 340: I 449- I 454.

38. Kang SS, Wong PW, Malinow MR: Hyperhomocysteinemia as a risk factor for occlusive vascular disease. Annu Rev Nutr 1992, 1 2:279-298.

39. Ueland PM, Refsum H, Brattstrom L: Plasma homocysteine and cardiovascular disease. In: Atherosclerotic cardiovascular disesase hemotasis, and endothelial function Edited by: Rancis RB Jr. New York: Marcel Dekker; 1992:183-236.

40. Bots ML, Launer LJ, Lindemans J, Hofman A, Grobber DE: Homocysteine, atherosclerosis and prevalent cardiovascular disease in the elderly: the Rotterdam study. J Int Med 1997, 242:339-347.

4I. Choumenkovitch SF, Selhub J, Wilson PW, Rader JI, Rosenberg IH, Jacques PF: Folic acid intake from fortification in United States exceeds predictions. J Nutr 2002, 132:2792-2798.

42. Hall JG, Solehdin F: Folic acid for the prevention of congenital anomalies. Eur J Pediatr 1998, I57:445-450.

43. Bailey LB, Rampersaud GC, Kauwell GP: Folic acid supplements and fortification affect the risk for neural tube defects, vascular Disease and cancer: evolving science. J Nutr 2003, 133:196IS-1968S.

44. Rampersaud GC, Bailey LB, Kauwell GP: Relationship of folate to colorectal and cervical cancer: Review and recommendations for practitioners. J Am Diet Assoc 2002, 102: 1273-1282.

45. French AE, Grant R, Weitzman S, Ray JG, Vermeulen MJ, Sung L, Greenberg M, Koren G: Folic acid food fortification is associated with a decline in neuroblastoma. Clin Pharmacol Ther 2003, 74:288-294.

\section{Pre-publication history}

The pre-publication history for this paper can be accessed here:

http://www.biomedcentral.com/1471-2393/4/20/prepub
Publish with Biomed Central and every scientist can read your work free of charge

"BioMed Central will be the most significant development for disseminating the results of biomedical research in our lifetime. "

Sir Paul Nurse, Cancer Research UK

Your research papers will be:

- available free of charge to the entire biomedical community

- peer reviewed and published immediately upon acceptance

- cited in PubMed and archived on PubMed Central

- yours - you keep the copyright

Submit your manuscript here:

http://www.biomedcentral.com/info/publishing_adv.asp 